\title{
Computational fluid dynamic analysis of blood flow through critical stenosis of the right coronary artery in human
}

\author{
Saba J.Muhseen ${ }^{\dagger}$ and Prof. Dr. Rafid M. Hannun * \\ ${ }^{\dagger}$ Mechanical Eng. Dept, College of Engineering, Thi-Qar University, Iraq \\ \$ Mechanical Eng. Dept, College of Engineering, Thi-Qar University, Iraq
}

\begin{abstract}
The aim of this paper is to predict the hemodynamics properties of blood flow during in the Critical stenosis RCA . This paper examines pulsed, laminar blood flow through state of the right coronary artery in patient heart. Data for these case were taken from a catheter laboratory in the Thi Qar Heart Center. The case for a man born in 1957 who has one stenosis in RCA with a stenosis of $80 \%$. A non-Newtonian blood model characterized by the Carreau equation was used, and a 3D model was used with the governing equations analyzed using the specified volumetric method. The SIMPLE algorithm has been adopted to link pressure and speed during runoff. Geometric figures are drawn using Auto CAD software and combined with FLUENT. The results showed that the speed increased significantly in the area of stenosis. Non-Newtonian viscosity increases its effect near the center of stenosis. The total pressure is equal to diastolic pressure with little increase. Keywords: Blood; Flow; Artery Stenosis; Pulsatile; Cardiovascular; Simulation; FVM
\end{abstract}

\section{Introduction}

Recent developments in the field of computational fluid dynamics CFD have capability to simulate the blood flow in the cardiovascular $(\mathrm{CV})$ system. Computer can be show the flow pattern of blood for a various disease artery. Therefore, CFD nowadays becomes a clinical diagnostic tool for the medical practicing throughout the region of vascular diseases. [1]

The physical laws can be used to simulate blood flow in the stenosis arteries. So in this study a transient simulation of actual case of right coronary artery (RCA) have been used with the aim of providing best understanding and modeling of blood flow through arteries. The aim behind this is to compare the effects of blood viscosity models on the pressure, velocity, and WSS distributions in RCA during the cardiac cycle .

D. Young and F. Tsai (1973)[2] Carried out laboratory experiments on static flow. Where the use of axial and asymmetric plastic models that have different contraction lengths and different area ratios. The Reynold number was obtained from the range of approximately 100 to 5000 . In this study, they showed a strong influence of geometry (size and shape) on the flow characteristics. As the throat approaches the stenosis and reaches its limit, the shear stress of the wall will increase slightly at the source of the throat. Where it is important for the flow with a low Reynold number is laminar and there is no separation run but when Reynold's number increases, the Laminar flow remains with the rotation zone .Ahmed and Giddens(1983)[3] Used geometric shapes to describe the stenosis and These forms are axisymmetric with $75 \%$ and $50 \%$ and $25 \%$ area reductions . Results obtained using Reynolds numbers (500 - 2000) and with the help of laser Doppler anemometers note the flow transform into turbulence for $75 \%$ were reduction. In addition, When the number of Reynolds increases from 500 to 1000 , the recycling area increases. S. Cavalcanti et al. (1992) [4] Used two different models in length and a stenosis which is a solid mesh wall with a reduction of $86 \%$, The first model has a narrowing 4.8 degree angle and the other 9.5 degree. They considered the flow constant within the narrowing of symmetric axial arteries .There is three equal distance points of the stenosis of pressure measured . one in the downstream of stenosis and another in upstream and middle of stenosis . Their findings were the middle-downstream pressure drop $\left(5.49 \mathrm{mmHg}\right.$ when $9.5^{\circ}$ taper angle and 10.51 $\mathrm{mmHg}$ when taper angle $4.8^{\circ}$ ) was Less than the upstreammiddle pressure drop $\left(78.92 \mathrm{mmHg}\right.$ when $9.5^{\circ}$ taper angle and $74.81 \mathrm{mmHg}$ when taper angle $4.8^{\circ}$ ). They concluded that upstream pressure is greatly affected by area occlusion but does not depend of tapering degree .Q. Long et al. (2001) [5] Obtained the behavior of blood flow after stenosis, by using a straight tube with stenosis and the blood flow is pulsed. They modeled three symmetrical and three asymmetrical stenosis models with area occlusion of $75 \%$ , $50 \%$ and $25 \%$. The flow was deem to be laminar, tube walls were rigid and $3 \mathrm{D}$. The numerical analysis was loaded out in CFX founded on the FVM . They discovered that the post stenosis flow was affected by the geometry of stenosis and degree of stenosis . In asymmetric models post stenosis flow was less sensitive to the change of area construction percent than in axi-symmetrical models. Finally, the stenosis effect length is shorter in the asymmetrical models than in axi-symmetrical models . H. Jung et al. (2004)[6] look into the characteristics of symmetric and pulsatile of blood flow through artery with symmetric stenosis ,and by using 75\%, 57\% and 50\% area decrease the effects of stenosis acuity and wall shear stress (WSS). Blood was modeled as non-Newtonian fluid based on Carreau viscosity model. Unsteady Navier-Stokes equations( NSE) are solved numerically by using Finite 
volume method (FVM) . They showed that when stenosis severity increase more than $57 \%$ the asymmetric flow can be uncovered in the separated flow region after stenosis. Moreover, they found that the non-dimensional peak velocity exponentially increases at a given severity of stenosis, and that high WSS near the stenosis region of the artery due to the fast flow. Dietiker and Hoffmam (2006)[7] made comparison between non- Newtonian and Newtonian flow behaviors and that is through a computational simulation for 3D pulsate blood flows in arteries with varying degrees of stenosis using FLUENT. The study was conducted for two geometries of the artery : a sharpened artery with stenosis and a circular artery with two consecutive bends. Blood was modeled as nonNewtonian fluid based on Carreau viscosity model. They found that the flow in an artery with two successive bends had a flat velocity profile of the non- Newtonian fluid compared with parabolic profile of the Newtonian fluid. In a sharpened artery with stenosis showed increases WSS near the stenosis and appeared flow separation after throat of stenosis .also indicated that the higher value of WSS causes harm to the endothelium layer, This is because they showed $50 \%$ diameter reduction causes damage to the endothelium layer. Seo (2013)[8] Used two different carotid artery model geometries (First geometry model was typical carotid and second model was internal and external carotid artery branches of the bifurcation joined in parallel to each other ) in the numerical simulations of blood flow through them. The governing equations solved using FLUENT . assumed uniform steady flow velocity inlet equal to $0.1325 \mathrm{~m} / \mathrm{sec}$ with 86 uniform time steps per cardiac cycle, used Carreau mode to describe NonNewtonian behaviour of blood. He estimated the arterial bifurcation geometry was reason it that the difference of the flow characteristics, clearly showed that in internal carotid artery the reversed flow region of second model is 2.5 times larger than that of first model. In the comparison between Newtonian and Non- Newtonian results good agreement in the velocity profiles, whilst some contradiction were found in pressure and WSS distributions due to shear thinning behaviour. Bhandwal and Ranjan (2017)[9] Studied, Blood flow was studied through a stenosis artery that was validated and simulated in varying blockages from $(50 \%$ 90\%). They used Carreau-Yasuda model to describe NonNewtonian behaviour of blood through a stenosis artery . Their findings were showed characteristics of developing laminar flow in the geometry with $90 \%$ blockage. That could be $90 \%$ blockage in an artery can be so dangerous, which can result in rupture of atherosclerotic plaque in the stenosis and drove to thrombosis or blood clotting. Blood clotting can cause nearly complete or complete stoppage of blood flow through the artery.

The aim of this paper is to predict the hemodynamics properties of blood flow during in the Critical stenosis RCA and examines pulsed, laminar blood flow through state of the right coronary artery in patient heart.

\section{Mathematical Model}

The result of diagnostic catheterization of patient number two indicates that the patient has a Critical stenosis and the degree of stenosis is $80 \%$ as shown Fig. 1 .

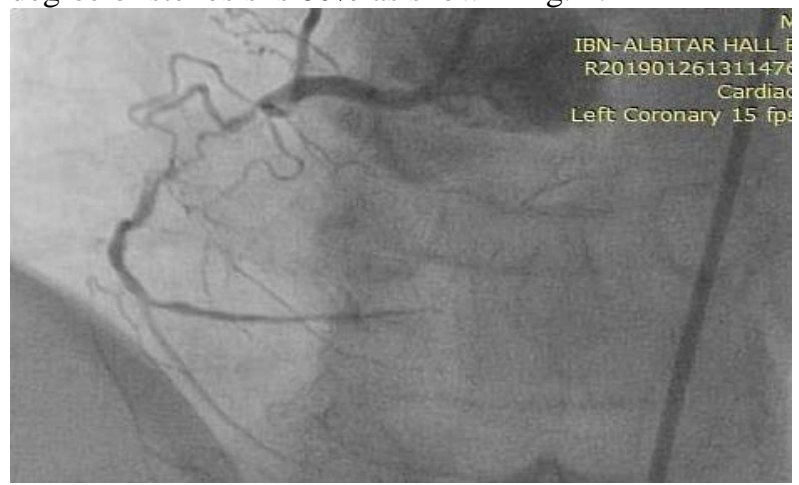

Fig.1 : Critical stenosis of the Right Coronary Artery.

\subsection{Pressure Values:}

When catheter reaches RCA, pressure values for RCA appear in monitor's screen .As Table (1) shows.

Table (1) : Pressure values for critical stenosis

\begin{tabular}{|c|c|}
\hline $\begin{array}{c}\text { Systolic } \\
\text { Pressure }(\mathrm{mmHg})\end{array}$ & $\begin{array}{c}\text { Diastolic } \\
\text { Pressure (mmH) }\end{array}$ \\
\hline 140 & 90 \\
\hline
\end{tabular}

\subsection{Models Description:}

As noted from angiogram in Fig (1), Coronary arteries (RCA) in the human body is ordinarily bend and curve. It also noted that the physical geometry of an artery very complex .three-dimensional (3D) non-Newtonian fluid laminar blood flow through RCA is numerically simulated. A formal representation of the computational range for patient are presented in Fig.(2) .

AutoCAD 2014 software is used for modeling right coronary arteries, with a scale suitable with RCA dimensions. The diameter of the coronary arteries is different along the artery, so select specified lines along the artery to show blood flow results through it. Table (2) explain diameter values for the fixed lines and equivalent length values from inlet blood flow to lines location .

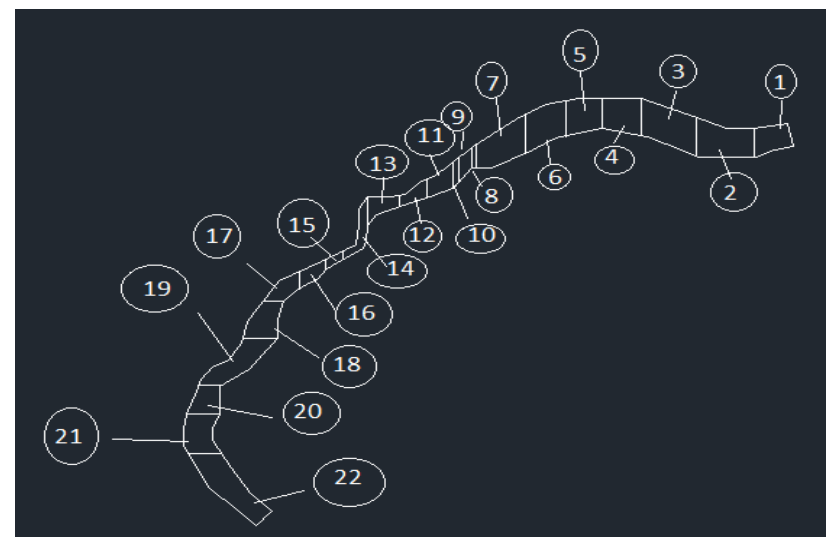

Fig .(2) Sections of the critical stenosis artery of the RCA 
Table (2) : Critical stenosis RCA dimensions.

\begin{tabular}{|l|l|l|}
\hline Sections & \multicolumn{1}{|c|}{ Diameter } & $\begin{array}{c}\text { Section } \\
\text { Length }(\mathrm{mm})\end{array}$ \\
\hline Section 1 & 4 & $0-3$ \\
\hline Section 2 & 3 & $3-7.8$ \\
\hline Section 3 & 3.9 & $7.8-12.4$ \\
\hline Section 4 & 3.6 & $12.4-15.7$ \\
\hline Section 5 & 2.9 & $15.7-18.6$ \\
\hline Section 6 & 3.5 & $18.6-21.9$ \\
\hline Section 7 & 3.8 & $21.9-26$ \\
\hline Section 8 & 2.3 & $26-26.4$ \\
\hline Section 9 & 2 & $26.4-27.5$ \\
\hline Section 10 & 2.4 & $27.5-30.1$ \\
\hline Section 11 & 1.8 & $30.1-32.4$ \\
\hline Section 12 & 1.1 & $32.4-35$ \\
\hline Section 13 & 2.7 & $35-36$ \\
\hline Section 14 & 0.8 & $36-61$ \\
\hline Section 15 & 1.1 & $61-62.5$ \\
\hline Section 16 & 1.7 & $62.5-64.7$ \\
\hline Section 17 & 1.6 & $64.7-67.1$ \\
\hline Section 18 & 2.9 & $67.1-71.4$ \\
\hline Section 19 & 1.7 & $71.4-76.1$ \\
\hline Section 20 & 2.7 & $76.1-79$ \\
\hline Section 21 & 2.8 & $79-82.9$ \\
\hline Section 22 & 2.4 & 82.9 \\
\hline
\end{tabular}

\section{Assumptions:}

1. The flow is $3 \mathrm{D}$ and unsteady state.

2. Constant temperature.

3. Incompressible flow (constant blood's density) .

4. Laminar blood flow with single phase .

5. Rigid right coronary artery(RCA) walls .

6. Negating the effect of gravity and body forces .

\section{Governing Equations:}

The governing equations are mathematical equations to maintain the laws of physics. which are applied to work out a solution based on flow properties and boundary conditions. The governing equations for unsteady state, incompressible, and three dimensions flow of blood as flow [10] :

The Continuity Equation:

$\frac{\partial u}{\partial x}+\frac{\partial v}{\partial y}+\frac{\partial w}{\partial z}=0$

------ (1)

The Momentum Equations:

$X$-Direction:

$\frac{\partial u}{\partial t}+u \frac{\partial u}{\partial x}+v \frac{\partial u}{\partial y}+w \frac{\partial u}{\partial z}=-\frac{1}{\rho} \frac{\partial p}{\partial x}+\mu\left(\frac{\partial^{2} u}{\partial x^{2}}+\frac{\partial^{2} u}{\partial y^{2}}+\right.$

$\left.\frac{\partial^{2} u}{\partial z^{2}}\right)$

$----(2)$
Y-Direction:

$\frac{\partial \mathrm{v}}{\partial t}+u \frac{\partial v}{\partial x}+v \frac{\partial v}{\partial y}+w \frac{\partial v}{\partial z}=-\frac{1}{\rho} \frac{\partial p}{\partial y}+\mu\left(\frac{\partial^{2} v}{\partial x^{2}}+\frac{\partial^{2} v}{\partial y^{2}}+\right.$

$\left.\frac{\partial^{2} v}{\partial z^{2}}\right) \quad----(3)$

Z-Direction

$\frac{\partial w}{\partial t}+u \frac{\partial w}{\partial x}+v \frac{\partial w}{\partial y}+w \frac{\partial w}{\partial z}=-\frac{1}{\rho} \frac{\partial p}{\partial z}+\mu\left(\frac{\partial^{2} w}{\partial x^{2}}+\frac{\partial^{2} w}{\partial y^{2}}+\right.$ $\left.\frac{\partial^{2} w}{\partial z^{2}}\right) \quad--(4)$

\subsection{Model boundary and initial conditions:}

The following boundary conditions were used to complete the model:

\subsubsection{Initial Condition}

At first $(\mathrm{t}=0)$ no flow takes place when the system is at rest.

\subsubsection{Boundary Conditions}

As stated by the foregoing assumptions , the boundary conditions $(t>0)$ for the laminar blood flow through RCA designate in the Fig.(1) can be show as follows:

\section{Inlet RCA:}

At the inlet of RCA steady parabolic velocity profile is imposed. The outlet velocity is provided in a sine wave form Equation for the pulsatile flow, and it is represented by the following equation [11]:

$U(t)=0.25\left[1+\sin \left(2 \pi\left(\frac{t}{T}\right)\right)\right]$

Where $\mathrm{T}$ is the period of oscillation and $\mathrm{t}$ is a local time. In the

present study $\mathrm{T}=0.8 \mathrm{~s}$.

\section{Outlet RCA}

In the present study, using the diastolic pressure readings as an inlet boundary condition. Table(3) shows diastolic pressure readings that appear in monitor's screen when catheter reaches RCA.

Table(3) diastolic pressure readings

\begin{tabular}{|c|c|}
\hline RCA state & $\begin{array}{l}\text { diastolic } \\
(\mathrm{mmHg})\end{array}$ \\
\hline $\begin{aligned} \text { Critical } & \text { stenosis } \\
\text { with } \mathrm{CR} 80 \% & \end{aligned}$ & 90 \\
\hline
\end{tabular}

\section{RCA Walls:}

The rigid walls of the RCA The density of artery is 960 $\mathrm{kg} / \mathrm{m}^{3}$ [12] and no-slip condition is imposed on the velocities.

\section{Carreau Model (Non Newtonian flow):}

Non- Newtonian blood flow is modeled as Carreau viscosity model. The complex rheological behaviour of blood is using a shear-thinning model by Carreau model [13]
$\mu=\mu_{\infty}$
$\left.(\lambda \dot{\gamma})^{2}\right]^{(n-1)^{2}}$
$\left.\mu_{\infty}\right)$
$[1+$

Where: $\mu \infty$ infinite shear viscosity, $\mu 0$ is zero shear viscosity, $\lambda$ is time constant, $\gamma$ is the shear rate tensor, $\mathrm{n}$ flow behavior index . 
For blood flow [13]:

$\mu_{0}=0.056$ Pa.s,$\mu_{\infty}=0.0035$ Pa.s,$\lambda=3.313 \mathrm{~s}$ and $\mathrm{n}=0.6$.

For $\dot{\gamma}$, a scalar measure of the rate of deformation tensor as $[14,13]$ :

$$
\dot{\gamma}=\sqrt{\frac{1}{2} \sum_{i} \sum_{j} d_{i j} d_{j i}} \quad=\sqrt{\frac{1}{2}\left(d_{i j}: d_{j i}\right)}
$$$$
\text { ------- (7) }
$$

And

$d_{i j}=\left(\frac{\partial u_{i}}{\partial x_{j}}+\frac{\partial u_{j}}{\partial x_{i}} \quad\right)=\left[\begin{array}{lll}d_{x x} & d_{x y} & d_{x z} \\ d_{y x} & d_{y y} & d_{y z} \\ d_{z x} & d_{z y} & d_{z z}\end{array}\right]$ (8)

Where $d i j$ is the rate of deformation tensor [15].

$d_{x x}=\frac{\partial u}{\partial x}, \quad d_{x y}=d_{y x}=\frac{1}{2}\left(\frac{\partial v}{\partial x}+\frac{\partial u}{\partial y}\right), \quad d_{x z}=d_{z x}=$ $\frac{1}{2}\left(\frac{\partial w}{\partial x}+\frac{\partial u}{\partial z}\right)$

$d_{y y}=\frac{\partial v}{\partial y}, d_{y z}=d_{z y}=\frac{1}{2}\left(\frac{\partial w}{\partial y}+\frac{\partial v}{\partial z}\right)$

$d_{z z}=\frac{\partial w}{\partial z}$

The double dot product of $d i j$ with itself gives:

$\frac{1}{2}\left(d_{i j}: d_{j i}\right)=d_{x x} d_{x x}+d_{x y} d_{y x}+d_{x z} d_{z x}+d_{y x} d_{x y}+$ $d_{y y} d_{y y}+d_{y z} d_{z y}+d_{z x} d_{x z}+d_{z y} d_{y z}+$

$$
d_{z z} d_{z z}
$$

By substation eqs.( 3.7 ) in eq.( 3.8 ), can be obtain:

$\frac{1}{2}\left(d_{i j}: d_{j i}\right)=2\left(\frac{\partial u}{\partial x}\right)^{2}+2\left(\frac{\partial v}{\partial y}\right)^{2}+2\left(\frac{\partial w}{\partial z}\right)^{2}+\left(\frac{\partial v}{\partial x}+\frac{\partial u}{\partial y}\right)^{2}+$ $\left(\frac{\partial w}{\partial x}+\frac{\partial u}{\partial z}\right)^{2}+\left(\frac{\partial w}{\partial y}+\frac{\partial v}{\partial z}\right)^{2}$

In this study three-dimensional $(\mathrm{x}, \mathrm{y}, \mathrm{z})$ so we use equation (11) as it is. By substation eq.(11) in eq.(7),the final shape for the shear rate tensor is:

$$
\begin{aligned}
& \therefore \dot{y}=\left[2\left(\frac{\partial u}{\partial x}\right)^{2}+2\left(\frac{\partial v}{\partial y}\right)^{2}+2\left(\frac{\partial w}{\partial z}\right)^{2}+\left(\frac{\partial v}{\partial x}+\frac{\partial u}{\partial y}\right)^{2}+\left(\frac{\partial w}{\partial x}+\right.\right. \\
& \left.\left.\frac{\partial u}{\partial z}\right)^{2}+\left(\frac{\partial w}{\partial y}+\frac{\partial v}{\partial z}\right)^{2}\right]^{2}
\end{aligned}
$$

\section{Numerical model:}

There are many numerical methods used in a numerical solution such as:
* Finite volume method
* Finite element method
- Finite difference method

The CFD software package ANSYS FLUENT 18.2 is applied to solve the mathematical model used in the present study to simulate blood flow through RCA.

\section{Results and Discussion}

The flow pattern is characterized by a small forward flow during systole wave with a large forward flow during diastole wave. The waveform in Fig.(3) represent velocity equation at artery outlet and can be divided into four different phases; early systole, peak systole, early diastole and peak diastole [12].
In the present study the representative of a cyclic phenomenon is simulated in time. Early diastolic corresponds to $\mathrm{t} / \mathrm{T}=(0-0.25)$, then it undergoes the acceleration phase and arrive peak velocity at $\mathrm{t} / \mathrm{T}(0.25-0.5)$ which is a peak diastolic. Flow enters the deceleration phase, early systolic corresponds to $\mathrm{t} / \mathrm{T}=(0.5-0.75)$ and peak systolic corresponds to $t / T=(0.75-1)$.

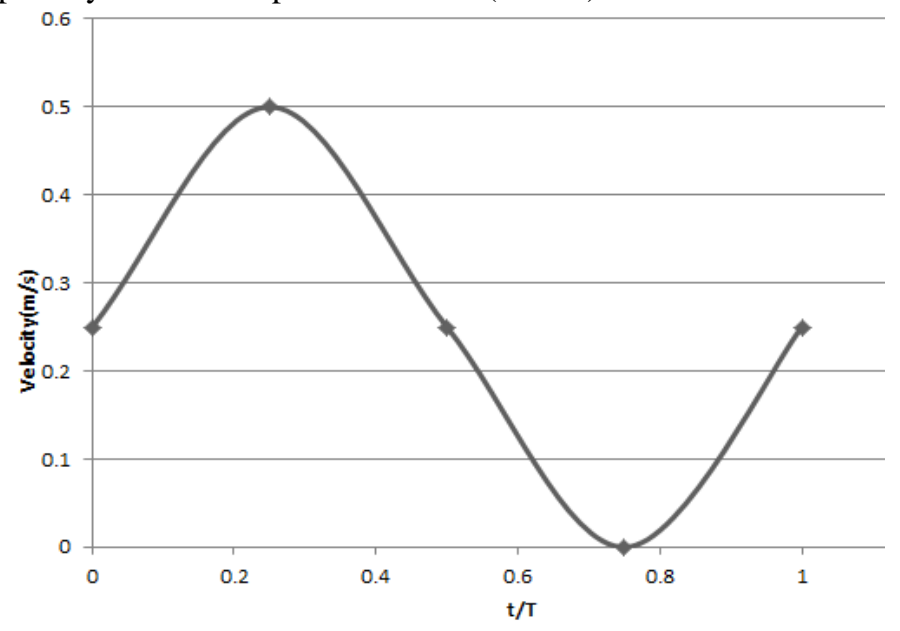

Figure. (3): Velocity waveform at the

artery inlet.

Rate the input velocity according to the pulse velocity shown above . Early diastolic corresponds to velocities $(0.25) \mathrm{m} / \mathrm{s}$, then it undergoes the acceleration phase and arrive peak velocity $(0.5,0.35) \mathrm{m} / \mathrm{s}$ which is a peak diastolic. Flow enters the deceleration phase, early systolic corresponds to ( 0.05$) \mathrm{m} / \mathrm{s}$ and peak systolic corresponds to $(0.01) \mathrm{m} / \mathrm{s}$.

Numerical simulations were carried out for the flow field based on the FVM. Also, ANSYS FLUENT 18.2 program has been used to solve the governing equations to obtained the results of pressure, velocity, viscosity and WSS distributions of laminar blood flowing for two cases of RCA. The results of the program were for three cardiac cycles to ensure reproducibility of the pulsed characteristic flow.

shown in figures (4)-(8). The largest gradient of velocity occurs at the two pulse velocities $(0.35,0.5)$. They have the same velocity values and indicate that the peak diastolic phase reaches its peak early at the pulse speed $0.35 \mathrm{~m} / \mathrm{s}$ i.e at the time period $\left(\frac{t}{T}=0.125\right)$ From the cardiac cycle . Peak continues until the pulse speed reaches $0.5 \mathrm{~m} / \mathrm{s}$ at $\left(\frac{t}{T}=0.25\right)$

It is noticed from the velocity diagram (9) during the lengths of the sections $(10,11,12,13,14,15,16)$ that have large and many differences in the velocity values .The largest grades of velocity values occur at the pulse velocity $0.35 \mathrm{~m} / \mathrm{s}$, where the velocity begins to increase over the input velocity of $0.723 \mathrm{~m} / \mathrm{s}$ and reaches the highest value at segment (12) (see table (2)) equals $5.51 \mathrm{~m} / \mathrm{s}$.The resulting increase in velocity is due to the sudden narrowing of the diameter, where the artery segment shown in the diagram starts from diameter $2.4 \mathrm{~m} / \mathrm{s}$ at section (10) and reaches 
diameter $1.1 \mathrm{~m} / \mathrm{s}$ Section (12). After that, there is a sharp decrease in the speed of up to a value of $0.723 \mathrm{~m} / \mathrm{s}$ at the section (13), which is a pre-narrowing section of $80 \%$. The reason for the sharp decline in speed is the large area in that section. The reason for the sharp decline in speed is the large area in that section. A very severe narrowing of the artery occurs, and the narrowing is symmetrical along the $25 \mathrm{~mm}$ length and the narrowing diameter is $0.8 \mathrm{~mm}$. The narrowing causes an increase in the speed to a value of 8.24 $\mathrm{m} / \mathrm{s}$ and increases until the highest velocity in the artery $13.7 \mathrm{~m} / \mathrm{s}$. As a result of the arcing and curving of the artery down, a central force is created that limits the blood flow in the center. Then there is a gradual expansion in the diameter

of the artery, so the velocity begins with a gradual descending, as shown in the diagram (9). At the velocity ( $V_{1}=0.25 \mathrm{~m} / \mathrm{s}$ ), which is the early diastolic phase, we notice in the diagram (9) the highest value during the early phase is $9.44 \mathrm{~m} / \mathrm{s}$ at acute stricture, section (14). We also note in the diagram (4.17) that the slightest gradations of velocity occur at the two pulse velocities $\left(V_{4}=0.05, V_{5}=\right.$ $0.01) \mathrm{m} / \mathrm{s}$. They are considered to be among the systolic phase, which is characterized by little effect within the coronary arteries. The velocity gradients at $V_{4}$ are higher than the velocity gradients at $V_{5}$. This indicates the occurrence of the early systolic phase at the pulse velocity $0.01 \mathrm{~m} / \mathrm{s}$ and the peak systolic phase at the pulse velocity.

\section{Inlet Pulse Velocity $0.25 \mathrm{~m} / \mathrm{s}$}

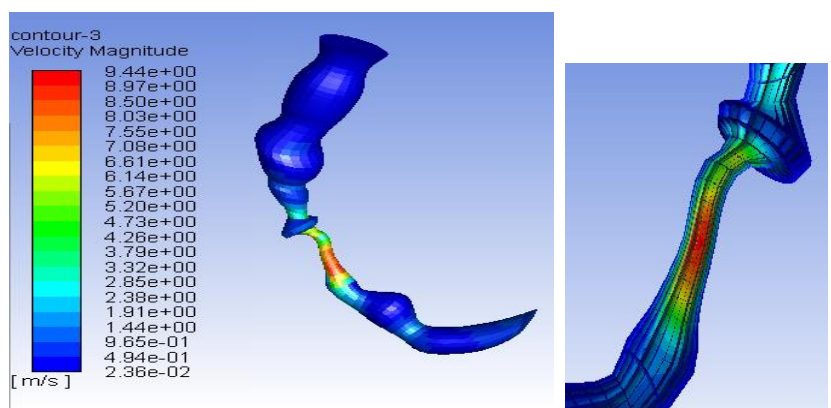

Fig .(4) Velocity counters critical stenosis of (RCA )

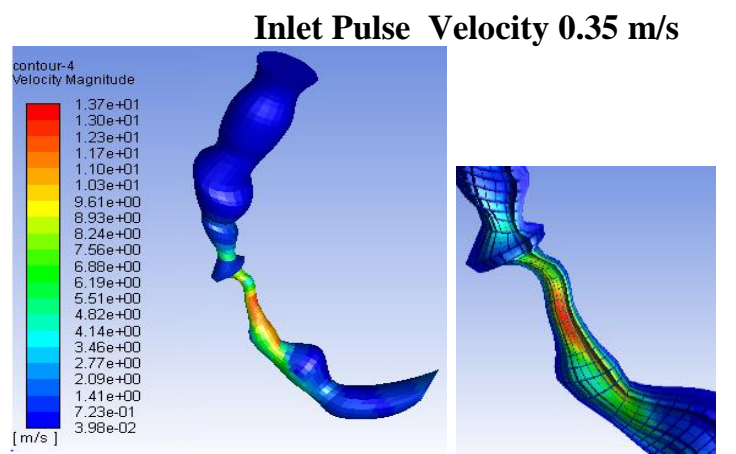

Fig. (5) Velocity counters critical stenosis of (RCA )

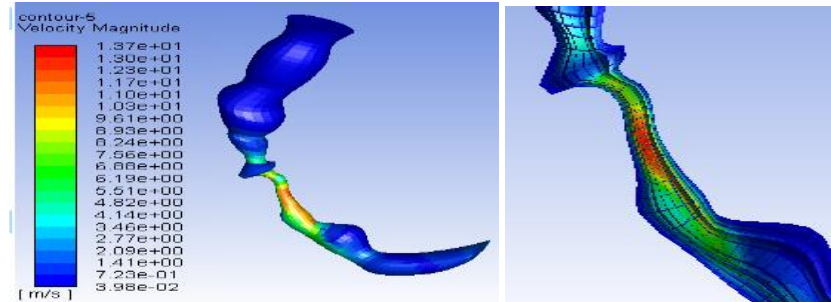

Fig. (6) Velocity counters critical stenosis of RCA

Inlet Pulse Velocity $0.01 \mathrm{~m} / \mathrm{s}$
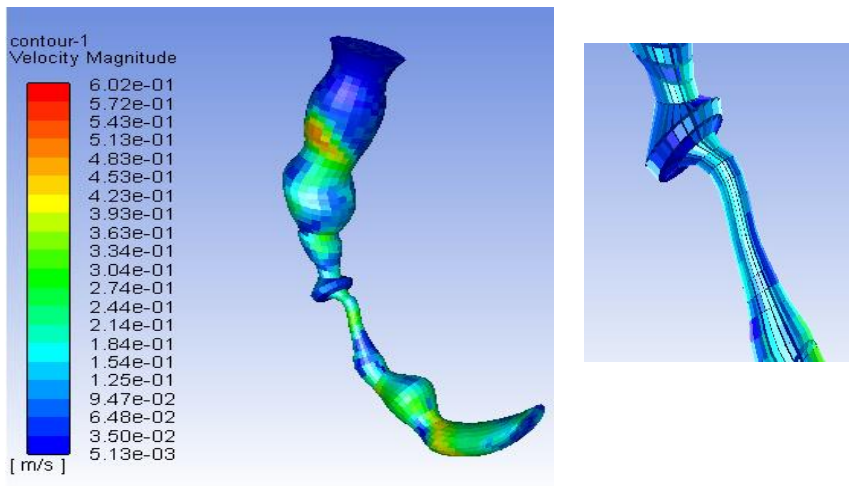

counters critical stenosis of RCA

Fig. (7) Velocity
Inlet Pulse Velocity $0.05 \mathrm{~m} / \mathrm{s}$

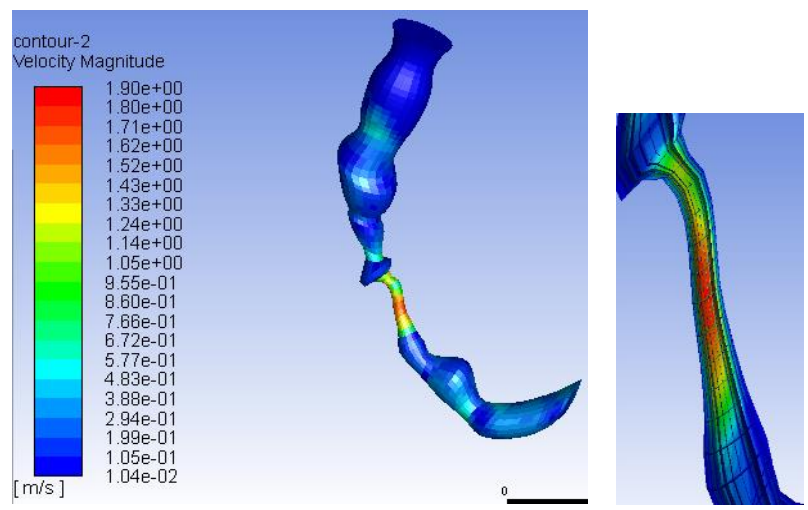

Fig. (8) Velocity counters critical stenosis of RCA 


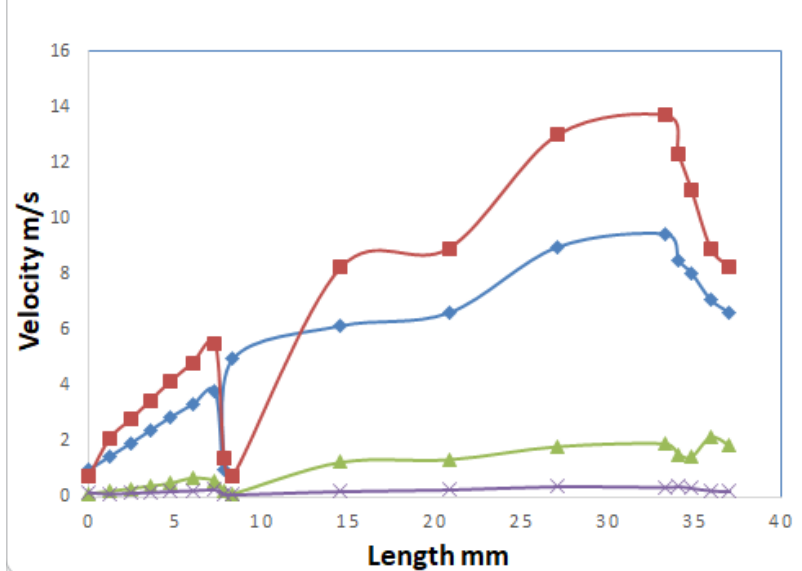

Fig. ( 9 ) Mean velocity of critical stenosis of RCA

As for the Non-Newtonian viscosity for stenosis artery, we notice from the diagram (4.26) significant differences in viscosity. It also shows that the viscosity is not affected by the pulse acceleration, as the lowest values for the wife are at the high pulse velocity $(0.5,0.35$ and 0.25$) \mathrm{m} / \mathrm{s}$. While the highest viscosity values are at the low pulse velocity $(0.05,0.01) \mathrm{m} / \mathrm{s}$. The value of the highest viscosity at the pulse velocity $(0.05 / \mathrm{sec})$ is about $0.0184 \mathrm{~m} / \mathrm{s}$ and it is expressed within the maximum viscosity values, where it is higher than the Newtonian viscosity and approaches zero shear viscosity (0.056 Pa.s) as specified within Carreau viscosity model equation( 6)

\section{Inlet Pulse Velocity $0.25 \mathrm{~m} / \mathrm{s}$}

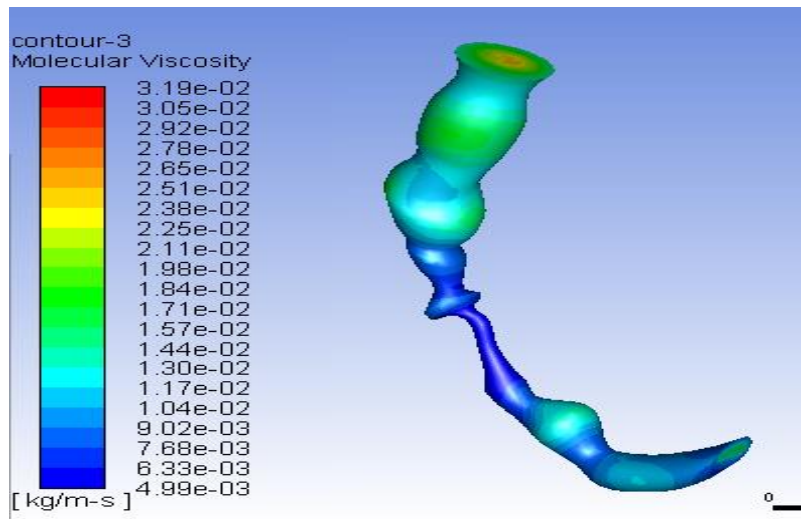

Fig. (10 ) Viscosity contours of critical stenosis RCA

Inlet Pulse Velocity $0.35 \mathrm{~m} / \mathrm{s}$

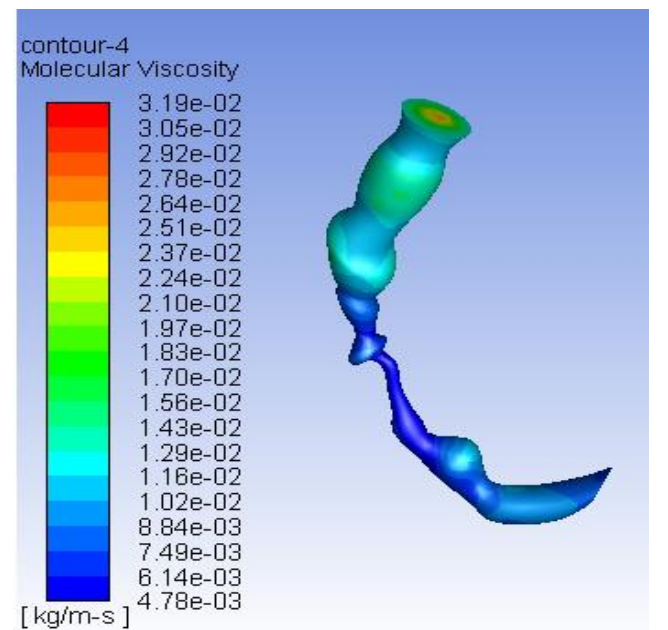

Inlet Pulse Velocity $0.5 \mathrm{~m} / \mathrm{s}$

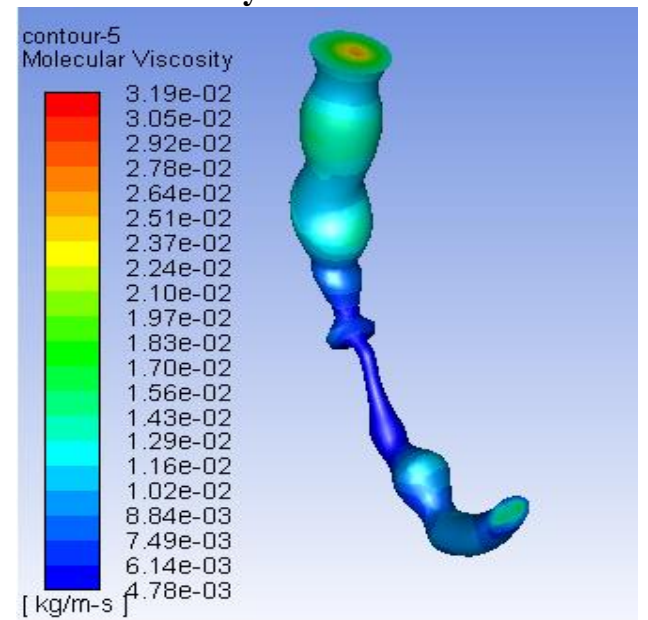

Fig. ( 11 ) Viscosity contours of critical stenosis RCA

Inlet Pulse Velocity $0.05 \mathrm{~m} / \mathrm{s}$

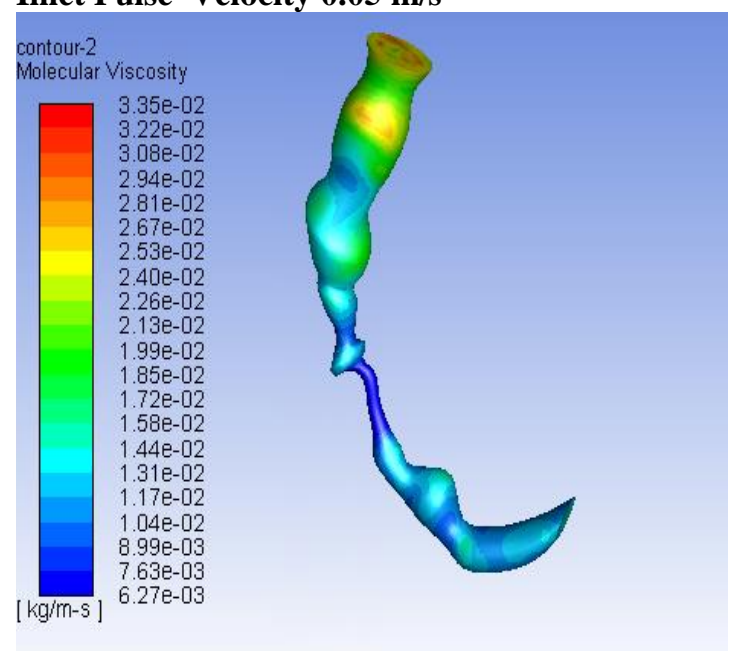

Inlet Pulse Velocity $0.01 \mathrm{~m} / \mathrm{s}$ 


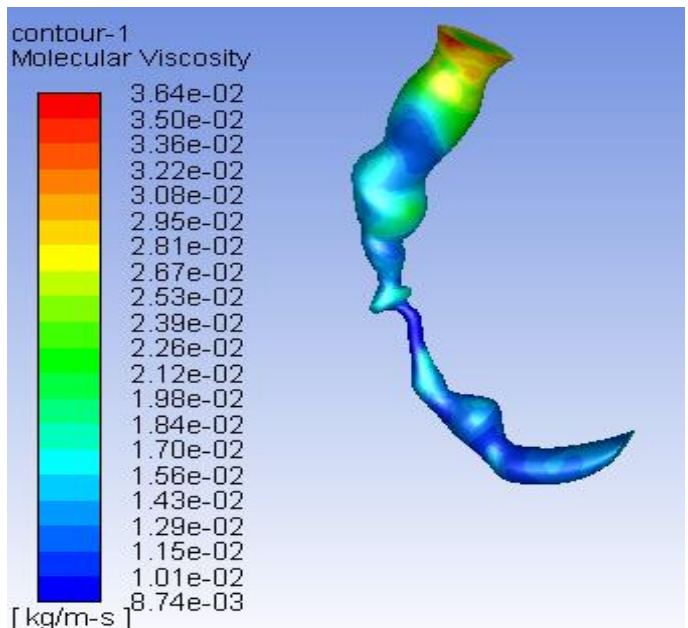

Fig. ( 12) Viscosity contours of critical stenosis RCA

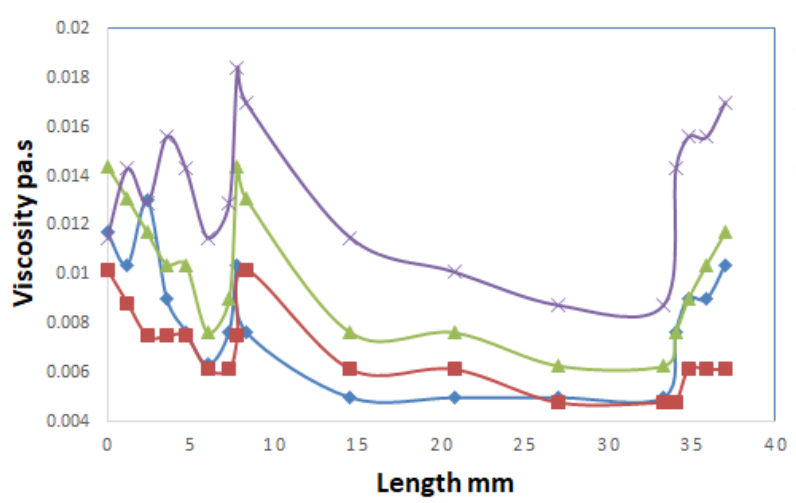

Fig . (13) distributions of critical stenosis RCA

The right coronary artery is irrigated in the blood during the diastolic phase. This means that the pressure within the RCA should be equal to the diastolic pressure [16].Fig. (4.27) present total pressure contours for Critical stenosis RCA .Where we notice the increase in the diastolic pressure in the stenosis artery ( $\mathrm{SR}=80 \%)$ increases from $90 \mathrm{~mm} \mathrm{Hg}$ to $96.91 \mathrm{~mm} \mathrm{Hg}$. See fig(4.28).

\section{Conclusions:}

The main conclusions from this thesis can be summarized as follows:

1. Increasing Stenosis ratio leads to increasing velocity and decreasing viscosity for blood flowing .

2. In stenosis part viscosity values decreases due to increasing shear rate which leads to increasing blood flow velocity .

3. Diastolic pressure within the RCA increased slightly.

4. Viscosity values are not severely affected by the speed of the pulse blood.

5. The behavior of hemodynamic variables affects the shape and curves of arteries .
6. At a stenosis of $80 \%$, the period of greatest velocity value increases during the peak diastole phase .

\section{References:}

[1] W. Chan, "Simulation of arterial stenosis incorporating fluid-structural interaction and non-Newtonian blood flow," M.Sc. thesis, Mechanical and Manufacturing Engineering RMIT University, 2006.

[2] D. Young and F. Tsai, "Flow characteristics in models of arterial stenoses-I. Steady flow," Journal of biomechanics, vol. 6, pp. 395-402, 1973.

[3] Ahmed, S. A., and Giddens, D. P., -Velocity Measurements in Steady Flow through Axisymmetric Stenosis at Modereate Reynolds Numbers, Journal of Biomechanics, Vol. 16, No. 7, 1983, pp. 505-516.

[4] S. Cavalcanti, P. Bolelli, and E. Belardinelli, "Pressure drops through arterial stenosis models in steady flow condition," Journal of Biomechanical Engineering Transactions ASME, vol. 114, pp. 416-418, 1992.

[5] Q. Long, X. Xu, K. Ramnarine, and P. Hoskins, "Numerical investigation of physiologically realistic pulsatile flow through arterial stenosis," Journal of biomechanics, vol. 34, pp. 1229-1242, 2001.

[6] H. Jung, J. Choi, and C. Park, "Asymmetric flows of non-Newtonian fluids in symmetric stenosed artery," Korea-Australia Rheology Journal, vol. 16, pp. 101-108, 2004.

[7] J. Dietiker and K. Hoffmann, "Computation of ThreeDimensional Blood Flows in Arteries," in Proceedings of 36 th AIAA Fluid Dynamics Conference, 2006, pp. 797-811. [8] T. Seo, "Numerical simulations of blood flow in arterial bifurcation models," Korea-Australia Rheology Journal, vol. 25, pp. 153-161, 2013.

[9] Singh Mukesh Roy, Basant Sikarwar*, Mohit Bhandwal and Priya Ranjan (2017)," Modelling of Blood Flow in Stenosed Arteries" 7th International Conference on Advances in Computing \& Communications, ICACC2017, 22- 24 August 2017, Cochin, India

[10] H. Versteeg and W. Malalasekera, "An Introduction to Computational

Fluid Dynamics", 1995.

[11] J. Dietiker and K. Hoffmann, "Computation of ThreeDimensional Blood Flows in Arteries," in Proceedings of 36 th AIAA Fluid Dynamics Conference, 2006, pp. 797-811. [12] COMSOL Models, "Fluid-Structure Interaction in a Network of Blood Vessels".

[13] Y. Cho and K. Kensey, "Effects of the non-Newtonian viscosity of blood on flows in a diseased arterial vessel. Part 1: Steady flows," Biorheology, vol. 28, pp. 241-262, 1991. [14] H. Jung, J. Choi, and C. Park, "Asymmetric flows of non-Newtonian fluids in symmetric stenosed artery," Korea-Australia Rheology Journal, vol. 16, pp. 101-108, 2004.

[15] W. Graebel, "Advanced fluid mechanics": Academic Press, 2007. 
[16] Franz H. Messerli, MD,* Gurusher S. Panjrath, The JCurve Between Blood Pressure and Coronary Artery

Disease or Essential Hypertension, 2009. 